\title{
STUDY OF ARGON ADDITIVE IN A BEAM INJECTION TYPE \\ NEGATIVE ION SOURCE USING VUV EMISSION SPECTROSCOPY
}

\author{
Naoki Nakada* and Osamu Fukumasa \\ Department of Electrical and Electronic Engineering, Faculty of Engineering, \\ Yamaguchi University, Tokiwadai 2-16-1, Ube 755-8611, Japan \\ *e-mail : z059fe@stu.cc.yamaguchi-u.ac.jp
}

\begin{abstract}
Effects of Ar addition are studied by using a beam injection type negative ion source. With adding $\mathrm{Ar}, \mathrm{I}_{\mathrm{H}^{-}}$increases at low base $\mathrm{H}_{2}$ pressure. At high base $\mathrm{H}_{2}$ pressure, however, $\mathrm{I}_{\mathrm{H}^{-}}$decreases. VUV emission intensities also decrease at high base pressure. In other words, Ar addition is adverse effect for production of $\mathrm{H}_{2}(\mathrm{v}$ "). Therefore, decrease in $\mathrm{I}_{\mathrm{H}^{-}}$is caused by decrease in $\mathrm{H}_{2}\left(\mathrm{v}^{\prime \prime}\right)$. In $\mathrm{D}_{2}$ plasmas, variation patterns of plasma parameters and VUV intensities by Ar addition are nearly the same as ones in $\mathrm{H}_{2}$ plasmas. Even in low base pressure, however, enhancement of $\mathrm{I}_{\mathrm{D}^{-}}$is not observed.
\end{abstract}

Keywords : volume negative ion sources, VUV emission, vibrationally excited molecules 


\section{Introduction}

Sources of $\mathrm{H}^{-}$and $\mathrm{D}^{-}$negative ions are required for generating efficient neutral beams with energies in excess of $150 \mathrm{keV}$. In a volume $\mathrm{H}^{-}$source, most of $\mathrm{H}^{-}$ions are generated by dissociative attachment of slow plasma electron $\mathrm{e}_{\mathrm{s}}$ (electron temperature $\mathrm{Te} \leqq 1 \mathrm{eV}$ ) to highly vibrationally excited hydrogen molecules $\mathrm{H}_{2}$ (v") (effective vibrational level v" $\geqq$ 5 6). These $\mathrm{H}_{2}$ (v") are mainly produced by collisional excitation between ground state hydrogen molecules $\mathrm{H}_{2}\left(\mathrm{v}^{\prime}=0\right)$ and fast electron with energies in excess of $20 \mathrm{eV}$. Namely, $\mathrm{H}^{-}$ions are produced by the following two-step process [1].

$$
\begin{aligned}
& \mathrm{H}_{2}\left(\mathrm{X}^{1} \Sigma \mathrm{g}, \mathrm{v}^{\prime \prime}=0\right)+\mathrm{e}_{\mathrm{f}}(\mathrm{E} \geq 20 \mathrm{eV}) \rightarrow \mathrm{H}_{2}^{*}\left(\mathrm{~B}^{1} \Sigma \mathrm{u}, \mathrm{C}^{1} \Pi \mathrm{u}\right)+\mathrm{e}_{\mathrm{f}}{ }^{\prime} \\
& \mathrm{H}_{2}{ }^{*}\left(\mathrm{~B}^{1} \Sigma \mathrm{u}, \mathrm{C}^{1} \Pi \mathrm{u}\right) \rightarrow \mathrm{H}_{2}\left(\mathrm{X}^{1} \Sigma \mathrm{g}, \mathrm{v}^{\prime \prime} \neq 0\right)+\mathrm{h} v(\mathrm{VUV}) \\
& \mathrm{H}_{2}\left(\mathrm{v}^{\prime \prime} \geq 5\right)+\mathrm{e}_{\mathrm{s}}\left(\mathrm{T}_{\mathrm{e}} \leq 1 \mathrm{eV}\right) \rightarrow \mathrm{H}^{-}+\mathrm{H}
\end{aligned}
$$

where $\mathrm{H}_{2}{ }^{*}\left(\mathrm{~B}^{1} \Sigma \mathrm{u}, \mathrm{C}^{1} \Pi \mathrm{u}\right)$ is singlet electronically excited hydrogen molecules. Production of $\mathrm{D}^{-}$ions is believed to be the same as that of $\mathrm{H}^{-}$ions. To develop efficient $\mathrm{D}^{-}$ion sources, it is important to clarify production and control of $\mathrm{D}_{2}$ plasmas and to understand difference in the two-step process of negative ion production between $\mathrm{H}_{2}$ plasmas and $\mathrm{D}_{2}$ plasmas.

Concerning enhancement of negative ion production, effects of Ar addition have been studied by several authors [2][3][4]. In DC [2] and ECR [3][4] plasmas, with adding Ar gas to low or high base $\mathrm{H}_{2}$ pressure, electron density : ne goes up and electron temperature : Te is kept under $1 \mathrm{eV}$. That is to say, plasma parameters (ne and Te) are suitable for negative ions production. The $\mathrm{H}^{-}$ion production increases when $\mathrm{Ar}$ is added to low base $\mathrm{H}_{2}$ pressure, On the other hand, it decreases with adding Ar to high base $\mathrm{H}_{2}$ pressure although plasma parameters are suitable for $\mathrm{H}^{-}$ions production. In DC and ECR plasmas, with adding Ar to low base pressure, increase in $\mathrm{H}^{-}$ion production is caused by enhancement of ne. However, with adding 
Ar to high base pressure, why $\mathrm{H}^{-}$ion production is decreased is not clarified well.

So far, we have confirmed that excitation of $\mathrm{H}_{2}$ (v") depends on fast electrons with energy in excess of 15-20 eV by using VUV spectroscopy [5]. We have also discussed enhancement of negative ion production and isotope effect on $\mathrm{H}^{-} / \mathrm{D}^{-}$volume production by observing VUV emission intensities [6]. Using VUV spectroscopy is effective in observing the physical process on negative ion production [7].

In this paper, we study effects of Ar addition on $\mathrm{H}^{-} / \mathrm{D}^{-}$ion production with the use of the beam injection type negative ion source, where energy of primary electrons, i.e. $e_{\mathrm{f}}$ energy, is well controlled and varied. We discuss why the negative ion production decreases with adding Ar by observing VUV emission intensities. We also discuss isotope effect $\mathrm{ff}^{-} / \mathrm{D}^{-}$production.

\section{Experimental Apparatus}

Figure 1 shows a schematic diagram of the beam injection type negative ion source. The chamber made of stainless steel is divided by a mesh grid $(\mathrm{z}=0 \mathrm{~cm})$ into two regions, i.e. a driver plasma region and a target plasma region. The target plasma region is a conventional multicusp negative ion source equipped with both a magnetic filter $(\mathrm{z}=20 \mathrm{~cm})$ and a plasma grid. The magnetic filter field divides the target chamber into the source region (i.e. plasmas with injected high-energy electrons) and the extraction region (i.e. plasmas with low Te).

In the driver chamber, plasmas are produced by DC arc discharge between hot filaments and the chamber anode, which is grounded. Electrons in the plasmas are extracted and injected into the target chamber as an electron beam with controlled beam energy $\mathrm{eV}_{\mathrm{B}}$. In the target chamber, $\mathrm{H}_{2} / \mathrm{D}_{2}$ gases are introduced and plasmas are produced by collision of the injected electron beams with introduced gases. In the source region, the VUV emission measurements related to the $\mathrm{H}_{2}$ (v") or $\mathrm{D}_{2}$ (v") production, i.e. the process $(1 \mathrm{~b})$, are carried out by using the 
VUV spectrometer. The spectrometer was normally operated at a resolution of $0.1 \mathrm{~nm}$.

Plasma parameters are measured by using Langmuir probes. A magnetic deflection type ion analyzer is used for measurement of the extracted $\mathrm{H}^{-}$or $\mathrm{D}^{-}$ion currents. Plasma grid potential is kept earth potential.

\section{Experimental Results and Discussion}

\subsection{VUV spectrum}

Figure 2 shows the typical VUV spectra from both (a) $\mathrm{H}_{2}$ and (b) $\mathrm{D}_{2}$ plasmas. Intensity with 121.6 $\mathrm{nm}$ in $\mathrm{H}_{2}$ plasmas is the spectrum of Lyman $\alpha$. Because $\mathrm{H}$ and $\mathrm{D}$ are isotope, we believe that the spectrum of Lyman $\alpha$ from $\mathrm{D}_{2}$ plasmas is nearly equal to that from $\mathrm{H}_{2}$ plasmas as shown in Fig.2 (b). According to the numerical results $[1], \mathrm{H}_{2}(\mathrm{v}$ " $\geqq 5)$ are more effective for $\mathrm{H}^{-}$production. In Fig.2 (a), spectra leading to production of $\mathrm{H}_{2}\left(\mathrm{v}^{\prime \prime} \geqq 5\right)$ are ranged from 117.5 to $165 \mathrm{~nm}[7]$. Internal energy of deuterium molecules $\mathrm{D}_{2}(\mathrm{v}$ " $\geqq 8)$ are the same as that of $\mathrm{H}_{2}(\mathrm{v} " \geqq 5)$. Therefore, discussion on VUV spectra in $\mathrm{H}_{2}$ plasmas should be also applicable for discussion on VUV spectra in $\mathrm{D}_{2}$ plasmas. Namely, production of highly vibrationally excited deuterium molecules $D_{2}(v ")$ is related to the emission with the same wavelength range, i.e. $117.5 \sim 165 \mathrm{~nm}$. We obtain the total intensity of the VUV spectra by integrating from 110 to $170 \mathrm{~nm}$ in both $\mathrm{H}_{2}$ and $\mathrm{D}_{2}$ plasmas. In integration of VUV spectra, Lyman $\alpha$ is excluded because it is not concerned with production of negative ions. In the following sections, these integrated intensities are presented for discussing production of $\mathrm{H}_{2}$ (v") and $\mathrm{D}_{2}(\mathrm{v} ")$. 


\section{2 $\mathrm{H}^{-}$production in $\mathrm{H}_{2}$ plasmas}

We have measured the dependences of plasma parameters, VUV emission intensities and negative ion currents on $\mathrm{H}_{2}$ pressure in the range 1 to 4 mTorr, and on Ar additive pressure (10-50\%), for several values of $\mathrm{H}_{2}$ base pressure $(1,1.5,2,2.5,3,3.5$ and 4 mTorr). These results are shown in Figs. 3-5.

Figure 3 shows plasma parameters [(a) ne and (b) Te] with adding Ar to $\mathrm{H}_{2}$ plasmas. ne is increased at both low(1 and $2 \mathrm{mTorr})$ and high( 3 and $4 \mathrm{mTorr})$ base $\mathrm{H}_{2}$ pressures. Te is not changed, and kept under $1 \mathrm{eV}$. The value of Te is suitable for $\mathrm{H}^{-}$ion production at both low and high base pressures. Increase in ne is caused by the higher ionization cross section of $\mathrm{Ar}$ gas compared with that of $\mathrm{H}_{2}$ gas [4].

Figure 4 shows integrated intensities of VUV emission corresponding to the results in Fig. 3. Integrated intensities of the VUV emission are increased a little at low base $\mathrm{H}_{2}$ pressure, but they are decreased at high base $\mathrm{H}_{2}$ pressure. About VUV emission with adding Ar, Curran et al proposed the following hypothesis [8] i.e. the sequential energy transfer from the excited argon states through a photon to hydrogen singlet states. This energy transfer process would be the cause of enhanced highly excited vibrational population of hydrogen molecules. However, the phenomenon is not observed in this study. As shown in Fig. 4, intensities of VUV emission is not increasing but decreasing at high base $\mathrm{H}_{2}$ pressure. Contrary to the above hypothesis, it seems that the vibrational cooling is carried out with Ar addition. According to the results shown in Figs. 3 and 4, at low base pressure, VUV emission and plasma parameters are suitable for $\mathrm{H}^{-}$ions production.

Figure 5 shows negative ion currents $\left(\mathrm{I}_{\mathrm{H}^{-}}\right)$corresponding to the plasma conditions shown in Figs. 3 and $4 . \mathrm{I}_{\mathrm{H}^{-}}$is increased a little at low base pressure. However, $\mathrm{I}_{\mathrm{H}^{-}}$is decreased at high base pressure although ne and Te are suitable for $\mathrm{H}^{-}$ions production. Decrease in $\mathrm{I}_{\mathrm{H}^{-}}$is caused 
by decrease in VUV emission intensities, i.e. decrease in $\mathrm{H}_{2}$ (v") production.

It is confirmed experimentally that decrease in $\mathrm{I}_{\mathrm{H}^{-}}$at high base $\mathrm{H}_{2}$ pressure is caused by decrease in $\mathrm{H}_{2}$ (v") production. Concerning plasma parameters and $\mathrm{I}_{\mathrm{H}^{-}}$, our results shown in Figs. 3-5, have the same tendencies as ones in DC and ECR plasmas [2][3][4]. In DC plasmas, Ar addition does not affect VUV emission [2], and the cause of decrease in $\mathrm{H}^{-}$ion production at high base pressure is written nothing. But we think that decrease in $\mathrm{I}_{\mathrm{H}^{-}}$at high base pressure in DC and ECR plasmas is also caused by decrease in $\mathrm{H}_{2}(\mathrm{v}$ ") production.

\section{3 $\mathrm{D}^{-}$production in $\mathrm{D}_{2}$ plasmas and Isotope effect on $\mathrm{H}^{-} / \mathrm{D}^{-}$production}

Figs. 3 and 4 show plasma parameters [(a) ne and (b) Te] and integrated intensities of VUV emission in $\mathrm{D}_{2}$ plasmas. Plasma parameters and VUV emission with Ar addition in $\mathrm{D}_{2}$ plasmas are changed by the same manner as ones in $\mathrm{H}_{2}$ plasmas. At low base pressure, plasma parameters and VUV emission are suitable for $\mathrm{D}^{-}$ion production the same as ones in $\mathrm{H}_{2}$

plasmas. However, values of ne and Te in $\mathrm{D}_{2}$ plasmas are higher than ones in $\mathrm{H}_{2}$ plasmas with adding Ar or pure discharge but Te is kept under $1 \mathrm{eV}$. Values of integrated intensities of VUV emission in $\mathrm{D}_{2}$ plasmas are lower than ones in $\mathrm{H}_{2}$ plasmas with adding Ar or pure discharge.

Figure 5 shows negative ion currents $\left(\mathrm{I}_{\mathrm{D}^{-}}\right)$corresponding to the plasma conditions shown in Figs. 3 and 4. At low base pressure, $I_{D^{-}}$are not increased by $A r$ addition unlike $\mathrm{I}_{\mathrm{H}^{-}}$in $\mathrm{H}_{2}$ plasmas although plasma parameters and VUV emission are suitable for $\mathrm{D}^{-}$ion production. At high base pressure $\mathrm{I}_{\mathrm{D}^{-}}$decreases in its intensitiy as $\mathrm{I}_{\mathrm{H}^{-}}$does.

Difference in the values of ne between $\mathrm{H}_{2}$ and $\mathrm{D}_{2}$ plasmas [see Fig. 3 (a)] is caused by difference in mass between hydrogen ions and deuterium ions. Deuterium ions have larger mass than hydrogen ions. That is to say, wall loss time for deuterium ions is longer than one for hydrogen ions. Difference in the values of Te between $\mathrm{H}_{2}$ and $\mathrm{D}_{2}$ plasmas [see Fig. 3 (b)] 
is also explained by difference in mass. In inelastic collisions, electron energy loss with light neutral is larger than that with heavy neutral particles. Then the value of Te may be different between $\mathrm{H}_{2}$ and $\mathrm{D}_{2}$ plasmas.

Difference in the value of VUV emission intensities (see Fig. 4) is caused by difference in cross section of vibrational excitation associated with the process (1a) between hydrogen molecules and deuterium molecules. The cross section of $\mathrm{H}_{2}$ is larger than one of $\mathrm{D}_{2}$ [9]. So, integrated intensities of VUV emission in $\mathrm{D}_{2}$ plasmas are smaller than ones in $\mathrm{H}_{2}$ plasmas.

At low base pressure, $\mathrm{I}_{\mathrm{D}^{-}}$hardly increases compared with $\mathrm{I}_{\mathrm{H}^{-}}$in $\mathrm{H}_{2}$ plasma (see Fig. 5). But plasma parameters and VUV emission intensities in $D_{2}$ plasmas are changed by the same manner as ones in $\mathrm{H}_{2}$ plasmas (see Figs. 3, 4 and 5). In other words, plasma parameters and VUV emission intensities in $\mathrm{D}_{2}$ plasmas are suitable for $\mathrm{D}^{-}$ion production. We think that $\mathrm{Ar}$ addition can change collisional process for negative ion destruction and these processes are different between in $\mathrm{H}_{2}$ plasmas and $\mathrm{D}_{2}$ plasmas. However, this is an open question. The details are now under study.

\section{Summary}

The effect of Ar addition in the beam injection type $\mathrm{H}^{-} / \mathrm{D}^{-}$source is studied. In $\mathrm{H}_{2}$ plasmas, at low base $\mathrm{H}_{2}$ pressure, $\mathrm{I}_{\mathrm{H}^{-}}$is increased a little by $\mathrm{Ar}$ addition. However at high base $\mathrm{H}_{2}$ pressure, $\mathrm{I}_{\mathrm{H}^{-}}$is decreased although plasma parameters are suitable for $\mathrm{H}^{-}$ion production. At the same time, VUV intensities are decreased at high base $\mathrm{H}_{2}$ pressure. In other words, $\mathrm{Ar}$ addition at high base $\mathrm{H}_{2}$ pressure makes adverse effect on $\mathrm{H}_{2}$ (v") production.

In $\mathrm{D}_{2}$ plasmas, variation patterns of plasma parameters and VUV intensities due to $\mathrm{Ar}$ addition are nearly the same as ones in $\mathrm{H}_{2}$ plasmas. However $\mathrm{I}_{\mathrm{D}^{-}}$are not increased unlike $\mathrm{I}_{\mathrm{H}^{-}}$ even if at low base $D_{2}$ pressure. 
In the further, on enhancement of $\mathrm{H}^{-} / \mathrm{D}^{-}$production by Ar addition, experiments should be done with changing plasma production conditions $\left(\mathrm{V}_{\mathrm{B}}, \mathrm{I}_{\mathrm{B}}\right.$, and double plasma method).

\section{Acknowledgements}

The author would like to thank Y. Tauchi and J.Ohno for their assistance. A part of this work is supported by the Grant-in-Aid for Scientific Research from Ministry of Education, Culture, Sports, Science and Technology, Japan.

\section{References}

[1] O.Fukumasa, J. Phys. D22 (1989) 1668.

[2] M.Bacal, M.Nishiura, M.Sasao, M.Wada, M.Hmamabe, H.Yamaoka, Rev. Sci. Instrum. 73 (2001) 903.

[3] K.Fujioka, O.Fukumasa, Abstract of 30th IEEE International Conference on Plasma Science (Jeju, June 2, 2003) P.211.

[4] T. Sakai, O. Fukumasa, abstract of 7th APCPST \& 17th SPSM (Fukuoka, June 29-July 2, 2004) 01P-94

[5] O.Fukumasa, N.Mizuki and E.Niitani, Rev.Sci.Instrum 69 (1998) 995.

[6] O.Fukumasa, S.Mori, N.Nakada, Y.Tauchi, M.Hamabe, Y.Takeiri, Contrib Plasma Phys 44 No. 5-6 (2003) 516.

[7] W.G.Graham, J. Phys. D17 (1984) 2225.

[8] N.P.Curran, M.B.Hopkins, D.Vender and B.W.James, Plasma Sources Sci. Technol 9 (2003) 169.

[9] R.Celiberto, M.Capitelli, U.T.Lamanna, Chem. Phy 183 (1994) 101. 


\section{Figure captions}

Fig.1 Schematic diagram of the beam injection type negative ion source.

Fig.2 Typical VUV spectra from $(\mathrm{a}) \mathrm{H}_{2}$ and $(\mathrm{b}) \mathrm{D}_{2}$ plasmas. Experimental conditions are as follows: gas pressures $\mathrm{p}\left(\mathrm{H}_{2}\right)=\mathrm{p}\left(\mathrm{D}_{2}\right)=3$ mTorr, beam acceleration voltage $\mathrm{V}_{\mathrm{B}}=100 \mathrm{~V}$ and beam current $\mathrm{I}_{\mathrm{B}}=1.5 \mathrm{~A}$

Fig.3 Pressure dependence of plasma parameters at the negative ion production region $(\mathrm{z}=21.5 \mathrm{~cm})$ in $\mathrm{H}_{2} / \mathrm{D}_{2}$ plasmas, (a)electron density ne and (b) electron temperature Te. Experimental conditions are as follow: $\mathrm{V}_{\mathrm{B}}=100 \mathrm{~V}$ and $\mathrm{I}_{\mathrm{B}}=$ $1.5 \mathrm{~A}$.

Fig. 4 Integrated intensity of VUV emission spectra from $\mathrm{H}_{2} / \mathrm{D}_{2}$ plasmas, corresponding to the results in Fig. 3.

Fig. 5 Negative ion currents in $\mathrm{H}_{2} / \mathrm{D}_{2}$ plasmas, corresponding to the results in Figs.3 and 4. Extracted voltage $\mathrm{V}_{\mathrm{ex}}=600 \mathrm{~V}$ 


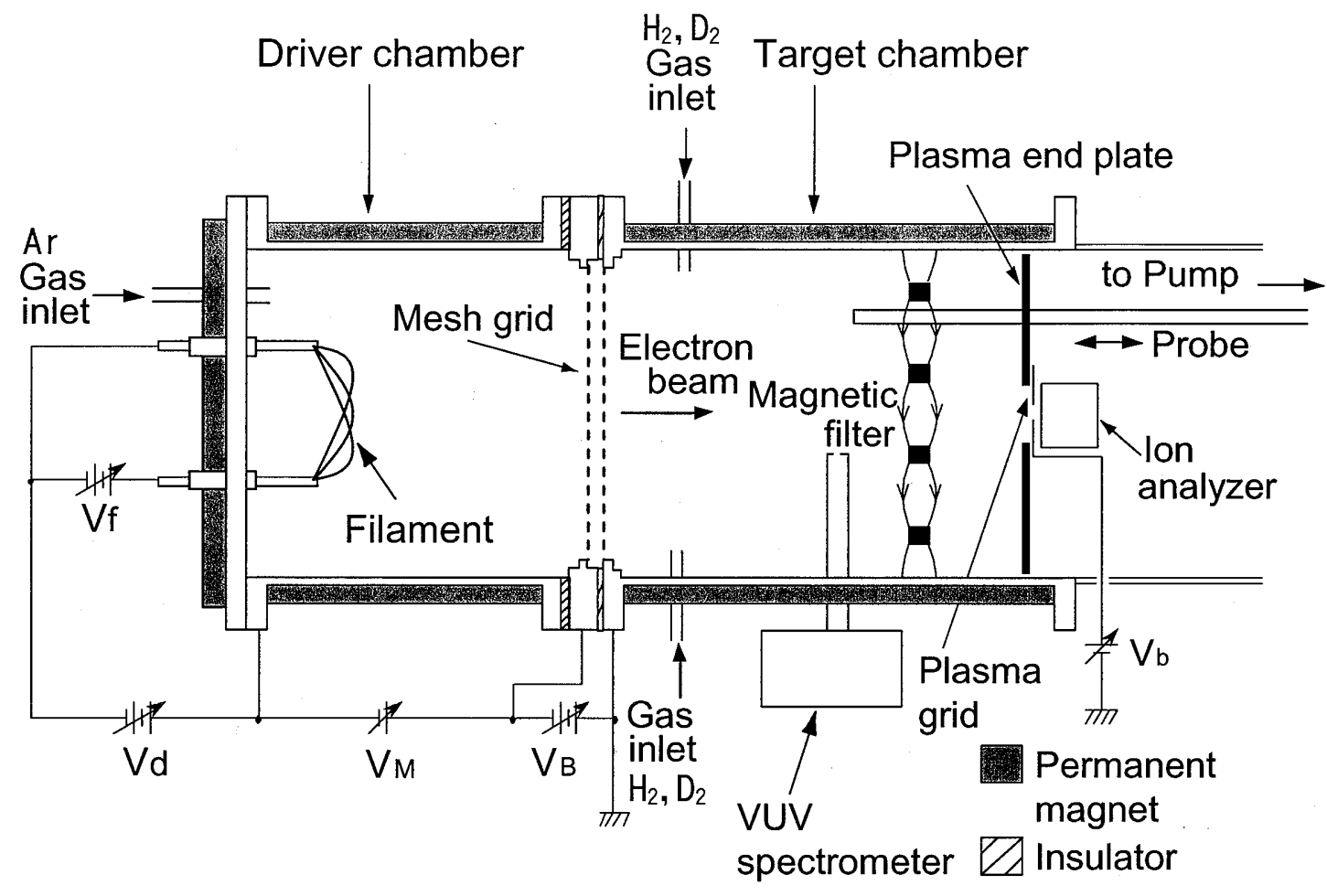

Fig.1 


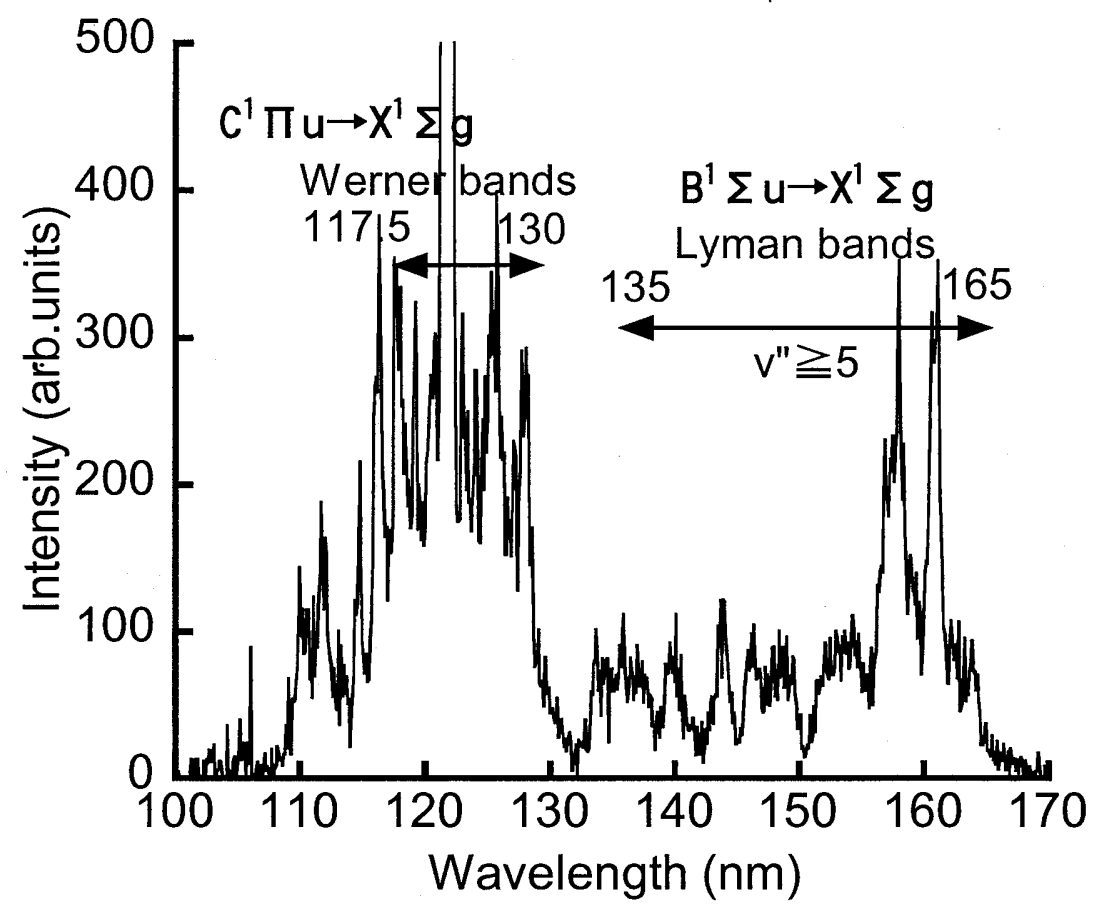

(a)

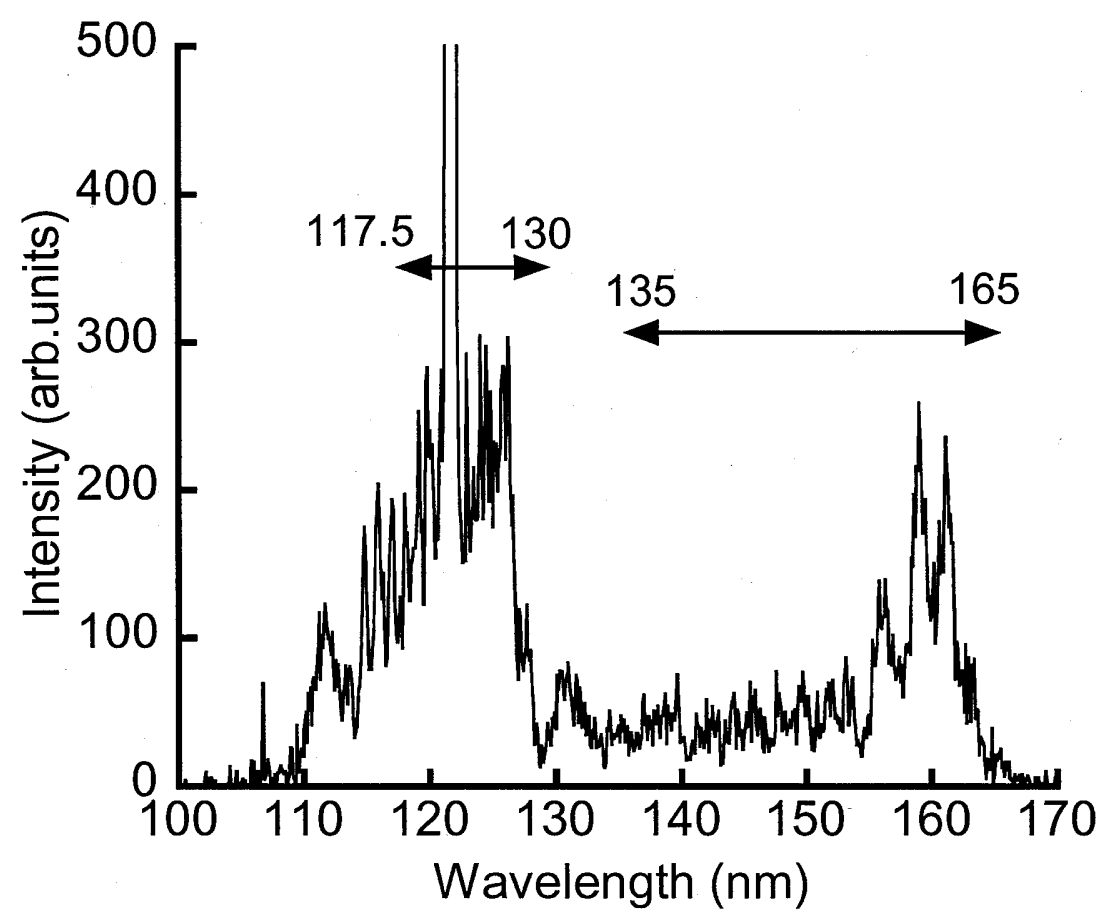

(b)

Fig.2 


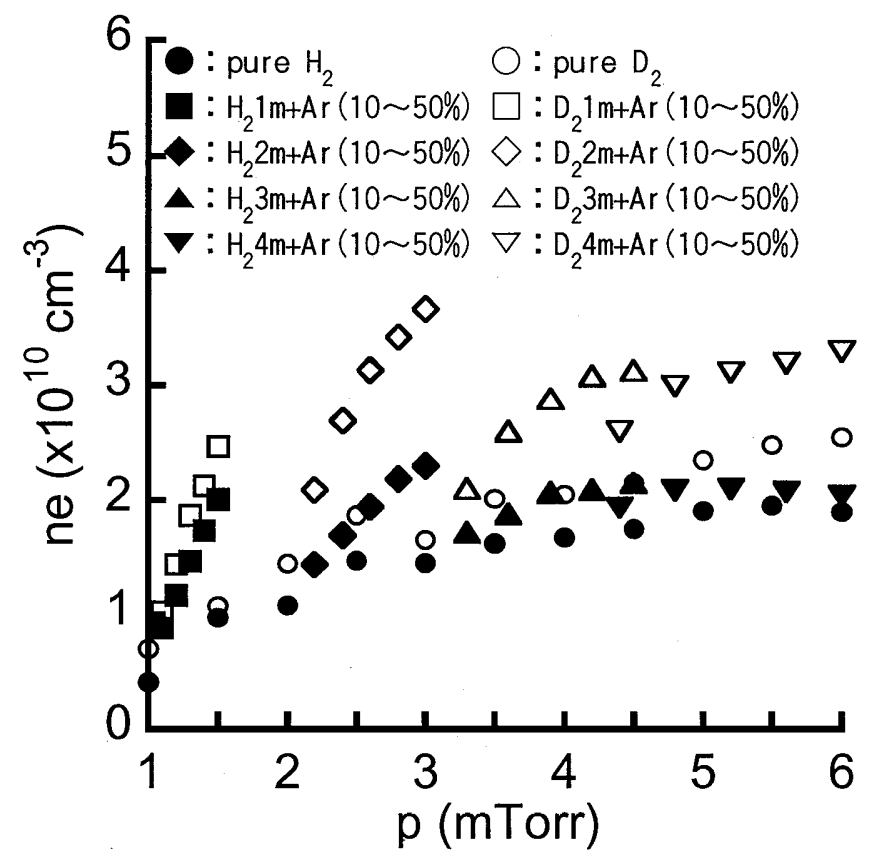

(a)

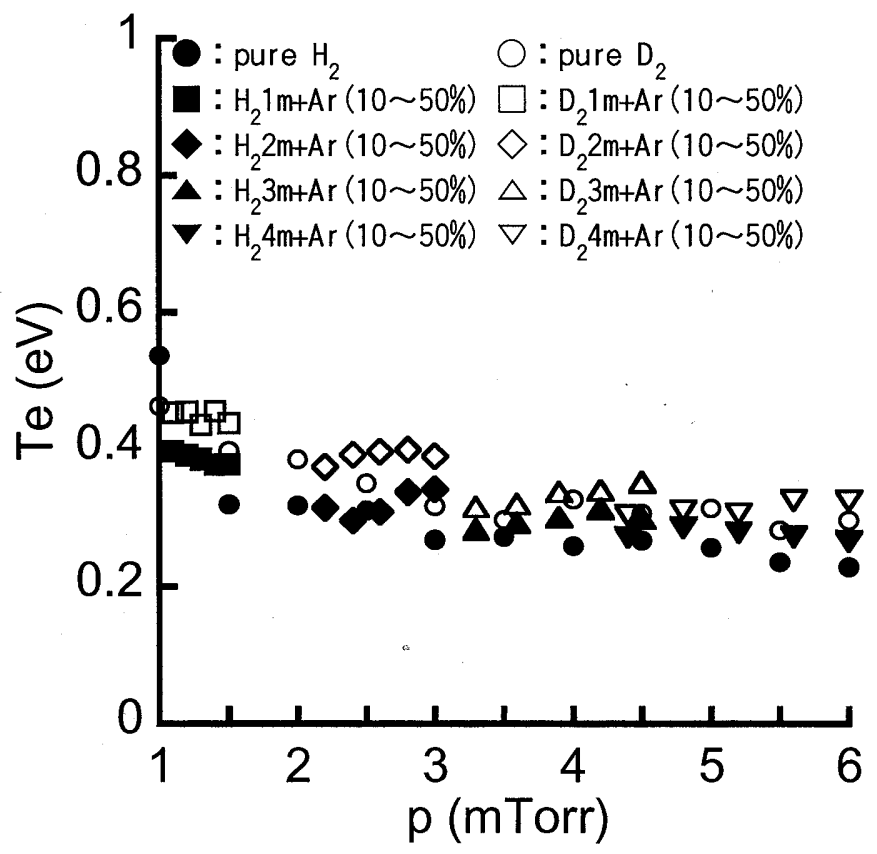

(b)

Fig. 3 


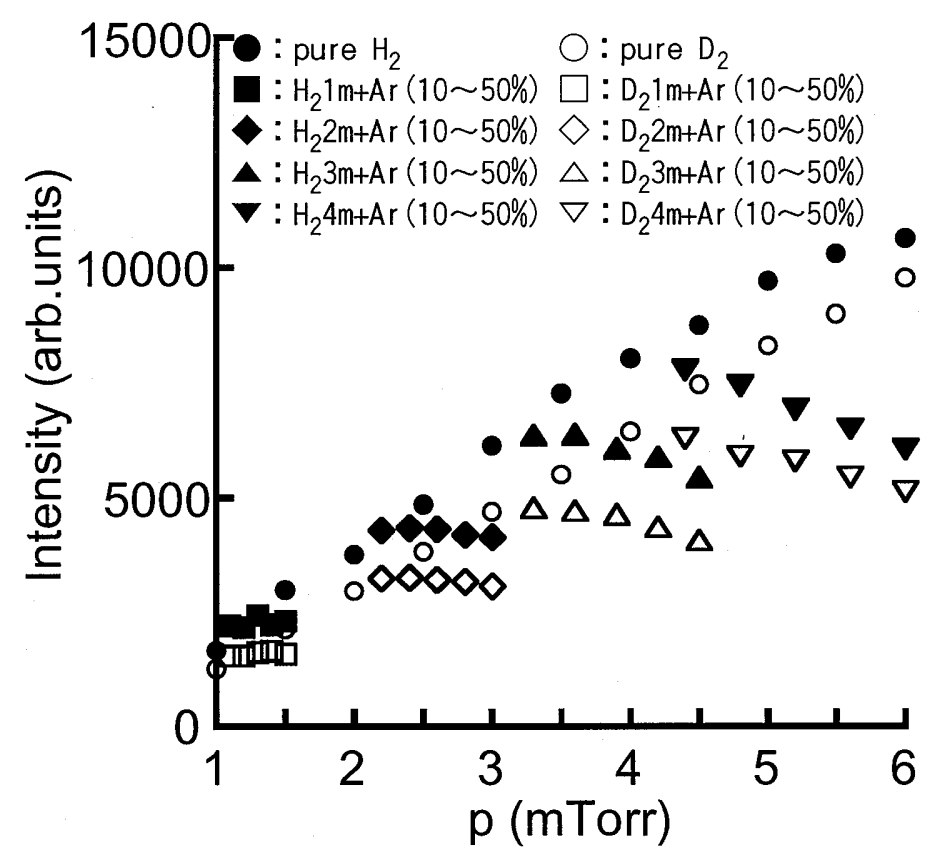

Fig.4

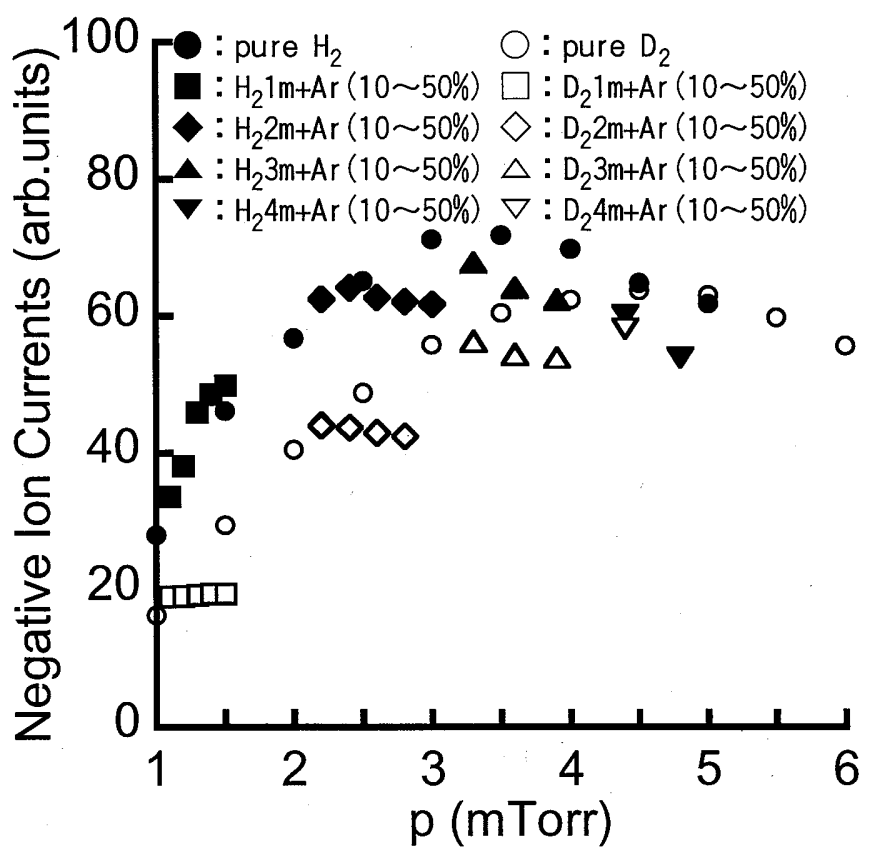

Fig. 5 